\title{
Heidegger en torno a Aristóteles. Una mirada fenomenológico-hermenéutica
}

\author{
Heidegger about Aristotle. \\ A Phenomenological-hermeneutic Look
}

\author{
CARMEN SEGURA PERAITA \\ Universidad Computense de Madrid
}

Recibido: 15/IV/2014 Aprobado definitivamente: 13/VII/2014

\section{RESUMEN}

En este estudio se muestra el interés de las interpretaciones heideggerianas sobre Aristóteles, tanto en sí mismas como por el rendimiento que tienen para el pensamiento de Heidegger. Se destaca que tales interpretaciones son siempre fenomenológico-hermenéuticas, lo que explica su singular carácter y orientación. Se insiste en que Aristóteles no es sólo determinante para el joven Heidegger, a través de su tratados de Ética y Retórica, sino también para el maduro, a través de la Física. Por último, se muestra la centralidad que detenta la discusión acerca de la ousía en el pensamiento heideggeriano.

\author{
PALABRAS CLAVE \\ OUSÍA-SENTIDO DIRECTIVO DEL SER- \\ PRESENCIALISMO-PHRÓNESIS-ENÉRGEIA
}

\begin{abstract}
This study shows the interest of the Heideggerian interpretations of Aristotle, both in their own selves as in the rendering of Heidegger's thinking. It emphasises that such interpretations are always phenomenological-hermeneutic, which explains their unique character and orientation.
\end{abstract}

(C) Contrastes. Revista Internacional de Filosofia, vol. XX No 2 (2015), pp. 231-249. ISSN: 1136-4076

Licenciatura de Filosofía, Universidad de Málaga, Facultad de Filosofía y Letras Campus de Teatinos, E-29071 Málaga (España) 
It insists that Aristotle is not only a decisive influence for the young Heidegger, through his analysis of the Rhetoric and Ethics, but also for his mature self, through the Physics. Finally, it demonstrates the centrality of the discussion of ousia in Heideggerian thinking.

KEYWORDS

OUSÍA, THE DIRECTIVE SENSE OF BEING, PRESENTIALISM, PHRÓNESIS, ENÉRGIA.

\section{INTRODUCCIÓN.}

EL INTERÉS DE LAS HEIDEGGERIANAS interpretaciones sobre Aristóteles está fuera de toda duda. Es necesario continuar, de manera rigurosa y sistemática, la tarea de estudiarlas críticamente, por dos razones. La primera es que ello contribuirá a una más lograda comprensión del pensamiento heideggeriano, la segunda es que las que podríamos denominar «variaciones heideggerianas sobre Aristóteles» iluminan con luz nueva cuestiones centrales de la filosofía actual.

La marcha de la publicación de la Gesamtausgabe, así como la misma importancia temática de la filosofía práctica de Aristóteles, ha ralentizado un tanto la investigación sobre aspectos centrales de su «filosofía teórica», determinantes para el pensar heideggeriano. Sin duda también hay estudios sobre este campo que han resultado fructíferos, ${ }^{1}$ pero sería necesario prestarles una mayor atención con vistas a un objetivo concreto: realizar un estudio de conjunto de las interpretaciones heideggerianas sobre Aristóteles. Este trabajo quiere aportar algunos elementos que lo harían posible. En primer lugar, hay que subrayar que la interpretación heideggeriana del estagirita es en todo momento «fenomenológico-hermenéutica», también después de la Kehre. En segundo lugar, es necesario mostrar que la nuclear noción aristotélica de ousía constituye el centro permanente de las reflexiones y críticas heideggerianas.

Es una noción «teórica» la que acapara de manera sostenida toda la atención de Heidegger. El joven Heidegger se vuelve contra ella porque imposibilita una comprensión práxica del ser en el mundo y porque bloquea una acertada visión del tiempo como horizonte para la comprensión del ser. Pero también el Heidegger posterior a la Kehre se mantiene beligerante con respecto a esta cuestión, ya que su antigua pregunta por el sentido directivo del ser permanece vigente. Su atención, volcada inicialmente en la Ética y en la Retórica se vuelve una vez más a la Física, el tratado en el que Heidegger encuentra los fundamentos suficientes para hallar en lo que es como dynamis y enérgeia el sentido directivo del ser.

1 Sadler, T., Heidegger and Aristotle. The Question of Being, Athlone, Londres, 1996; Denker, A. et alia (eds.), Heidegger und Aristoteles, München, Karl Abert Verlag, 2007; Hanley, C., Being and God in Aristotle and Heidegger y «Heidegger on Aristotle's 'metaphysical' God», Continental Philosophy Review, 32, 1, 1999, pp. 19-28. 
En consecuencia con lo dicho, en la primera parte de esta investigación me detendré brevemente en las interpretaciones sobre Aristóteles del joven Heidegger, particularmente en la crítica a la ousía. En la segunda parte, me ocuparé especialmente de la interpretación que el Heidegger maduro realiza sobre las centrales nociones aristotélicas de physis y enérgeia. Se trata de una lectura en absoluto «neutral», puesto que el autor de las Beiträge hace rendir dichas nociones para su proyecto central, que lleva por título, «Ereignis». Por último, mis consideraciones finales retornan sobre la problemática ousía. En ese momento, mi intención es doble, por una parte quiero mostrar que la diferente visión de Aristóteles y Heidegger se aclara desde la diferencia ontológica. Además realizaré algunas observaciones encaminadas a razonar la coherencia de la crítica e interpretación heideggeriana de la ousía.

\section{Primeros PUnTOS NEURÁlgicos DE LAS INTERPRETACIONES: \\ OUSÍA, PHRÓNESIS Y ALÉTHEIA.}

En los primeros años como docente son sus propias preguntas e inquietudes las que mueven a Heidegger a volver sobre Aristóteles. Convencido de que la situación hermenéutica de la filosofía es fruto de la tradición heredada, se ve en la necesidad de llegar a las raíces para hacer un diagnóstico acertado de dicha situación hermenéutica. ${ }^{2}$ Cuando en el denominado Natorp Bericht aborda esta tarea, concluye que las categorías que todavía hoy gobiernan la filosofía y con ella la inadecuada comprensión de la existencia humana, tienen su origen en la radicalización ontológica de la idea de movimiento. ${ }^{3}$

Esto que acabo de exponer constituye la razón última (en cuanto a la importancia) y primera (en sentido cronológico) por la que Heidegger comienza su debate con Aristóteles: que el pensador griego acuñó las categorías y metacategorías que han determinado toda la filosofía occidental. El estagirita habría elaborado estas categorías movido por la necesidad de dar cuenta de la experiencia originaria de la que surge toda su filosofía: el movimiento de la naturaleza. ${ }^{4}$ Así lo explica Heidegger en 1922 en el Informe Natorp. Años más tarde, en el parágrafo 6 de Sein und Zeit, su autor dirá que es la experiencia y concepción de los seres del universo lo que determina toda la filosofía aristotélica, en particular su concepción de la ousía y del tiempo. ${ }^{5}$ A esto es preciso añadir la tesis heideggeriana de acuerdo con la cual el modelo de la filosofía occidental, en general, y de la griega y aristotélica en particular, es el de la

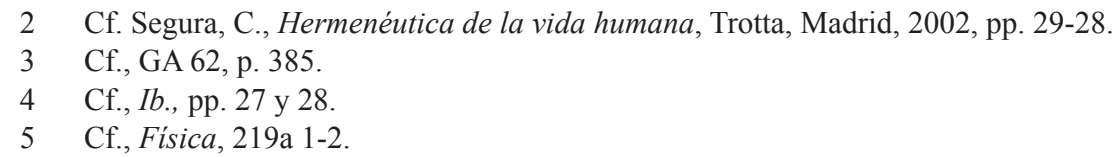


producción. Así lo sostuvo en cursos tan relevantes como el Sophistes, de 1924 y los Problemas fundamentales de la Fenomenología, de 1927.

Ahora bien, Heidegger entiende que la experiencia del movimiento no es válida para lograr una adecuada comprensión del Dasein humano, cuyo ser considera nuestro pensador en los primeros años 20' como el auténtico objeto de la filosofía. De hecho, la radicalización ontológica de la idea de movimiento habría conducido a Aristóteles a dos extremos «indeseados». Por una parte, le habría llevado a primar la sophía (el conocimiento de lo que es siempre y necesariamente) sobre la phronesis (el «conocimiento práctico» de lo que no es siempre ni necesariamente y que es el propio de Dasein). De esta manera, la dimensión contemplativa habría arrumbado la práctica, el carácter de «acción» y de «proyección» del ser humano ${ }^{6}$. Por otra parte, como ya se ha mencionado, habría dado lugar a las grandes metacategorías de acto y potencia, detentando el acto toda la primacía sobre la potencia. A su vez, el primado del acto haría de la de Aristóteles una metafísica «presencialista». ${ }^{7}$

Pero esto no es todo. La preponderancia de la contemplación sobre la acción habría propiciado a la larga una comprensión de la verdad alejada de la auténtica y originaria experiencia griega, inicialmente compartida por el mismo Aristóteles. Si a esto se le suma que, de acuerdo con el estagirita, el ser humano excelente es contemplación, se entiende que el pensador griego -y ante todo, la tradición que le sigue- acabara relegando la verdad práctica que él mismo había descubierto. Una verdad sin embargo prioritaria, con radicalidad ontológica, en el planteamiento filosófico de Heidegger.

Aunque sería necesario detenerse en estas interpretaciones, en este artículo no hay espacio para hacerlo. Por otra parte, las juveniles interpretaciones heideggerianas del estagirita ya han sido objeto de excelentes investigaciones. A lo que no es posible renunciar sin menoscabar el sentido de esta investigación es a un acercamiento a la interpretación y crítica heideggerianas de las nociones aristotélicas de sustancia y acto.

\section{II.1. OUSÍA Y ENÉRGEIA}

La acusación de presencialismo aparece por vez primera, aunque de manera latente, en el Informe Natorp y se hace expresa en la «Introducción» del Sophistes. En las líneas que siguen intentaré una aproximación a lo nuclear de la interpretación que le permite a Heidegger calificar como presencialista la metafísica aristotélica.

En el Natorp Bericht su autor ya había afirmado taxativamente que la sabi-

6 Cf., Natorp Bericht, GA 62, p. 374.

7 Heidegger, Sophistes, GA 19, p. 178. 
duría es el extremo de la tendencia al cuidado (Sorge), característica del Dasein. Es decir, había sostenido que en el origen de la sabiduría está la técnica. O lo que es lo mismo, que el modelo para la interpretación del universo es el de la producción. ${ }^{8}$ Que la técnica es el origen de la sabiduría significa que el sentido directivo del ser es el de la producción y que en consecuencia ser significa actividad actual, presente. Esto implica que el ser se entienda como «presencia» (Gegenwart, Anwesenheit) y explica que en una comprensión del ser obtenida mediante un criterio temporal el presente cobre la primacía absoluta. ${ }^{9}$ En su interpretación, Heidegger tiene en cuenta algo bien sabido. Para Aristóteles el sentido directivo del ser es el del ente que es siempre y necesariamente y no resulta difícil advertir que existe una neta vinculación entre ser siempre y presencia. De hecho, Aristóteles prefiere a los entes que son siempre porque, con terminología heideggeriana, son los auténticamente presentes (Anwesen).

Por otra parte, el pensador de Friburgo no encuentra dificultad en asociar explícitamente enérgeia y presencia. Entiende que lo presente es lo que está plenamente terminado y esto le permite vincular las ideas de ser producido (Fertigsein), enérgeia y presencia (Anwesenheit). De hecho, ser producido es tanto como ser presente y mantenerse así producido en la presencia (Fertganwesendsein)..$^{10}$ Así pues, la idea primera del Natorp Bericht-que se centraba en el carácter paradigmático de la producción-y la posterior del Sophistes -según la cual el ser es entendido como Anwesenheit- se unen para articular lo que, sin duda, Heidegger podría considerar una más ajustada interpretación de la enérgeia aristotélica. Aquélla que la entiende como presencia. ${ }^{11}$

Pocos años más tarde, en Ser y tiempo, su autor expresa de manera categórica el veredicto que ya había formulado antes sobre la ontología antigua.

Se nos hace manifiesto que la interpretación antigua del ser del ente está orientada por el «mundo»o, si se quiere, por la «naturaleza» en el sentido más amplio de esta palabra, y que, de hecho, en ella la comprensión del ser se alcanza a partir del «tiempo». La prueba extrínseca de ello -aunque por cierto sólo extrínseca- es la determinación del sentido del ser como parousía o como ousía con la significación ontológico-temporaria de «presencia». ${ }^{12}$

8 Esto es algo que mantendrá invariablemente a lo largo de los años, como sigue ocurriendo, por ej., en Die Grundprobleme der Phänomenologie, en «Von Ursprung des Kunstwerkes» o en «Die Zeit des Weltbildes».

9 Cf. Heidegger, Sophistes, GA 19, pp. 68-69. Cf. además, Segura, Carmen, Hermenéutica de la vida humana, Trotta, Madrid, 2002, p. 130.

10 Cf. Ib., p. 111.

11 Cf., Ib.

12 Heidegger, Ser y tiempo, Trotta, Madrid, 2003, traducción Jorge Eduardo Rivera, p. 25 (Sein und Zeit, GA 2, p. 34). Cf. también, pp. 34-35. 
No resulta difícil entender la razón por la que Heidegger vincula el mundo y el tiempo. Se trata de lo siguiente. La cosmología aristotélica fue determinante, tanto en su metafísica como en su ética. De acuerdo con aquella, en el universo podemos distinguir el mundo sublunar -al que pertenecen los entes que no son ni siempre ni necesariamente- y el mundo supralunar -al que pertenecen aquellos que son siempre y necesariamente. Está claro, por tanto, que la comprensión aristotélica del cosmos está guiada por un criterio temporal: los entes perfectos son siempre y no pueden no ser siempre, son pura presencia; los corruptibles, por el contrario, no son siempre y pueden no ser: pueden no estar o ser presentes.

No resulta difícil compartir la idea según la cual el tiempo es el criterio que rige la comprensión de la naturaleza y entender que ésta es también determinante para la comprensión del ser. De esa manera: como presencia pura. Tampoco resulta difícil advertir que enérgeia y ousía unifican sus significados en uno sólo: presencia. Ahora bien, si esto es así, tampoco resulta descabellado sostener que la metafísica, ahora en particular la aristotélica, es presencialista.

Heidegger se vio impelido a «destruir» aquella interpretación del ser que, a su juicio, conduciría a entenderlo como mera posición. Esto significa que las raíces del árbol kantiano se nutrían del humus aristotélico. Así lo entendió nuestro pensador en una etapa ya madura de su pensamiento, como se advierte en las interpretaciones recogidas en el Nietzsche a propósito de la cuestión que nos está ocupando. ${ }^{13}$

Por extraña que pueda parecer la afirmación que se acaba de mencionar, tiene su sentido si mantenemos presente la lectura que Heidegger realizó de Aristóteles en la «Introducción» de Ser y tiempo. Porque también desde el tiempo, desde el presente, entiende Kant la existencia, lo que está siendo ahora. A la vez, sabemos que para el filósofo de Königsberg esa existencia no es sino posición, realidad efectiva. En definitiva, que el ser sea concebido por ambos pensadores desde el tiempo es lo que hace viable la suposición heideggeriana de que en los orígenes de la reducción del ser a simple posición se encuentra la teoría aristotélica acerca de la ousía y ello aunque la comprensión del ser aristotélica fuera inicialmente distinta de la que la tradición llegó a elaborar.

Sabemos que el objetivo preciso de Heidegger, especialmente definido tras la Kehre, es mostrar que el ser es lo que se retrae, de manera que a él pertenece constitutivamente el ocultamiento; es decir, que el ser es aquello anterior, no presente ni representable, que constituye la misma posibilidad de la metafísica y ello de tal manera que ésta se yergue dejándolo atrás y a la espalda.

13 Cf., Nietzsche II, GA 6.2. Conviene atender a los primeros epígrafes del capítulo VIII, dedicado a «la metafísica como historia del ser» donde Heidegger analiza la transformación de la enérgeia en actualitas, de la verdad en certeza y del hypokeimenon en subjectum. 
[La metafísica] tendría que ser propiamente concernida por el ser mismo que ha penetrado en esa diferencia [entre el qué-es y el que-es]. El ser rehúsa, sin embargo, este concernir, y sólo así posibilita a la metafísica su comienzo esencial, en el modo de la preparación y despliegue de esta distinción. (...) Olvido del ser quiere decir, entonces: ocultarse de la proveniencia del ser». ${ }^{14}$

La producción es uno de los modos de lo que Heidegger denomina «presenciar». Este habría sido el horizonte y esquema de la metafísica occidental, primero en Aristóteles y más adelante en el pensamiento latino medieval que se construye en torno a la idea central de la creación, entendida como «producción» por parte de Dios desde la nada que pone a los seres extra causas. Y, como ya se puede advertir aquí, el ser de lo creado no es otra cosa que «posición». ${ }^{15}$

La otra manera de llevar a la presencia, esencialmente unida a la anterior y también emblemática de toda la metafísica occidental, es la representación. Así lo pondría de manifiesto su destino acontecido, en Descartes y tras él hasta el idealismo absoluto. La mejor manera que Heidegger tiene de mostrarlo es haciendo ver que el mayor exponente de la presencia, la sustancia, pasa, tras Aristóteles, de ser concebida como sujeto ontológico a serlo como sujeto lógico, como «sujeto apofántico» de todas las representaciones. Por esta razón se habría producido el «giro copernicano»: el centro ya no serían los entes, las cosas (tá prágmata) sino la conciencia, la subjetividad. ${ }^{16}$

Lo cierto es que, de acuerdo con Heidegger, la dinámica propia de la metafísica occidental no conduce sino a implementar el olvido del ser. El único eco que de él daría noticia es, precisamente, el que apenas se deja escuchar en la idea del ser como «realidad efectiva» (Wirklichkeit). Pero, también lo sabemos, «El ser no puede ser. Si fuera, ya no sería ser, sino ente (...). Ser: en realidad, lo que permite la presencia. ${ }^{17}$

En realidad, Heidegger no reprocha a Aristóteles el haber mostrado el estatuto presencial de lo que es ni el haber hecho del tiempo el criterio para la determinación de lo real. Tampoco hay rechazo de la comprensión aristotélica de lo real. Lo que más bien ocurre es que, más allá de lo óntico, en «diferencia ontológica» con ello y del lado de la nada, el ser se esencia. Ocurre que «ser» es, de acuerdo con Heidegger, algo más que cópula. La «fenomenológica ontología dinámica», hacia la que se encaminan los esfuerzos del de Friburgo, no

14 Heidegger, Nietzsche II, Destino, 2000, Barcelona, trad. Juan Luís Vermal, capítulo 8, p. 329 (GA 6.2, p. 402).

15 Cf., $I b .$, pp. 413ss.

16 Cf., Ib. Ver además, Segura, Carmen «Heidegger: la copertenencia entre Dasein y ser. Una confrontación con Kant», Pensamiento, vol. 67, n 252, (2011), pp. 295-320.

17 Heidegger, M., «La tesis de Kant sobre el ser», Hitos, op. cit., p. 387 (GA 9, p. 479). 
puede tener como último centro de referencia la ousía sino el acontecimiento (Ereignis).

\section{LA PREGUNTA POR EL SENTIDO DIRECTIVO DEL SER TRAS LA KEHRE.}

Heidegger anduvo a vueltas, muy desde el principio, con los sentidos aristotélicos de lo que es. ${ }^{18}$ En sus años de formación fue determinante la lectura de la obra de Brentano sobre la pluralidad de los sentidos del ser en Aristóteles. ${ }^{19}$ En ella Brentano ofrece una lectura univocista que nuestro autor suscribiría en su juventud -influido, como estaba, por la doctrina lógica de $\operatorname{Lotze}^{20}-$ y más tarde cuestionaría ${ }^{21}$. De cualquier manera, desde entonces la pregunta acerca del sentido directivo del ser pasó a ser una de las determinantes en su pensamiento. Así, Ser y tiempo podría ser también leído desde esta perspectiva.

Esa pregunta, «¿cuál es el sentido directivo del ser?», parte de la temprana negativa a admitir que lo sea la ousía. Pero, si no es ésta, ¿cuál entonces? En un primer momento, hasta comienzos de los años treinta-como se puede observar en Sein und Zeit y en Von Wesen der Wahrheit- el sentido directivo sería la verdad, ya lo hemos visto. Posteriormente Heidegger se inclina por la enérgeia (aunque atelés). Al hacerlo no olvida la alétheia, más bien proporciona una más lograda comprensión de la misma propiciada por su reflexión sobre el Ereignis. Así comienza a ponerse de relieve en las Beiträge zur Philosophie.

Ya ha sido mencionado que Heidegger estudió las nociones de dynamis y enérgeia en el Natorp Berich. Poco después, en el semestre de verano de 1926, Conceptos Fundamentales de Filosofía Antigua, encontramos un nuevo tratamiento del tercer libro de la Física ${ }^{22}$, ya abordado rápidamente en el Informe Natorp. ${ }^{23}$ En este curso Heidegger dedica a la Física un capítulo que trata de las centrales categorías de dynamis, enérgeia y entelécheia. Éstas aparecen claramente relacionadas con la de ousía como sentido directivo del ser. Un año más tarde, en 1927, nuestro pensador realiza una nueva interpretación fenomenológica de los primeros libros de la Física que comienza a distanciarse de las

18 Cf., Volpi, Franco, Heidegger y Aristóteles, Fondo de Cultura Económica, México, 2012, pp. 176 y 180.

19 Brentano, Franz, Von der mannigfachen Bedeutung des Seienden nach Aristoteles, Freiburg, Herder, 1862.

20 Cf., Volpi, Franco, Heidegger e Brentano, Padova, CEDAM, 1976. Cf. también, Segura, Carmen, «¿Hay una hermenéutica categorial en la Tesis de Habilitación de Martin Heidegger», en Ramón Rodríguez (ed.), Lenguaje y categorías en la hermenéutica filosófica, Biblioteca Nueva, Madrid, 2012, pp. 177-208.

21 Aunque, a mi parecer, nunca logró desembarazarse del planteamiento univocista.

22 Grundbegriffe der aristotelischen Philosophie GA 18, pp. 283-329.

23 Cf., NB, GA 61, p. 391-396. 
anteriores. Las nociones de dynamis y enérgeia continúan resultando decisivas. Algo que concuerda con su posterior interpretación del libro IX de la Metafísica; particularmente durante el curso de 1931, Aristoteles: Metaphysik IX. Von Wesen und Wircklichkeit der Kraft. Allí, Heidegger encumbra definitivamente el sentido de lo que es como la potencia y el acto por encima de la ousía. ${ }^{24}$ Por último, hay que destacar el pormenorizado análisis que realiza Heidegger en un conocido trabajo: "Von Wesen und Begriff der Physis. Aristóteles, Physik $B l »$, de 1939. Se trata de una extraordinaria interpretación a la que atenderé con cierto detalle en las líneas que siguen.

Aunque soy de la opinión de que no hay ruptura sino continuidad entre el Heidegger de los años veinte y el posterior a Ser y tiempo, he de admitir que su filosofía experimenta ciertamente un giro (Kehre). Tal giro pasa, entre otras cosas, por la negativa radical a otorgar al Dasein humano la centralidad que hasta entonces había tenido en su pensamiento. ${ }^{25}$ De hecho, ya en Sein un Zeit la «analítica existencial» no es sino el paso previo, aunque necesario, que abre y permite abordar la pregunta que interroga por el sentido del ser. Esto último habría de ser el verdadero objetivo de toda la investigación. El ser humano ya no será sino «el pastor del ser», Lichtung, ámbito espacio-temporal para el ocultamiento-desocultamiento del ser. ${ }^{26}$

En los albores de los años treinta, Heidegger renuncia a cualquier tipo de analítica existencial, descentra al Dasein; lo sitúa siempre al amparo y gobierno del ser que se retrae y abandonado a él. Esto implica la postergación de sus reflexiones críticas sobre la phrónesis y la sophía. Éstas corresponden a la primera etapa de su pensamiento y en ella dieron su fruto. Asunto bien diferente es el que tiene que ver con la ousía; su interpretación se prolonga a lo largo de todo el periplo heideggeriano vertebrando en gran parte el conjunto de su pensamiento. Y es que la reivindicación de la cuestión del ser y del sentido pasa por la destrucción de la noción aristotélica de sustancia. Porque la metafísica es presencialista, no puede ir más allá del ente y, por tanto, renuncia, por su propia constitución, destinalmente, a plantearse la cuestión del ser. Digamos que no lo hace porque, sencillamente, no puede hacerlo. De cualquier modo, sólo en el debate con la metafísica puede abrirse un espacio para lo único digno de ser pensado. Ésta es la razón por la que no puede haber «superación» de la metafísica. Es necesaria la confrontación permanente con ella para que al menos se haga presente la ausencia del ser; es decir, para que

24 Cf., Volpi, Franco, op. cit., p. 181. Aunque Volpi supo destacar la influencia de las nociones de physis y enérgeia en la definitiva comprensión del ser por parte de Heidegger, no llegó a relacionarlas directamente con el Ereignis.

25 Cf., Heidegger, Sein und Zeit, GA 13, p. 13.

26 Cf., Beiträge zur Philosophie (GA 65), n. 226; también, Grundfragen der Philosophie. Ausgewälte Probleme der Logik, GA 45, p. 351. 
comparezca como aquello impensado - por impensable- que se oculta y retrae ante cualquier intento de presentificación. Porque el ser no es. ${ }^{27}$

En consecuencia con lo dicho, los desarrollos que siguen se centran en la interpretación y apropiación heideggerianas de las nociones aristotélicas de physis y enérgeia. Porque ya adentrado en su camino del pensar, Heidegger alcanza una nueva comprensión de las grandes metacategorías de potencia y acto, que proporciona un extraordinario rendimiento para el despliegue de su noción de Ereignis. ${ }^{28}$ Con ella se refiere Heidegger a lo que hace posible la donación de ser, entendido como sentido y no, desde luego, como fundamento de lo ente. Al hacerlo esta evocando la parmenídea identidad de pensar y ser, que nuestro pensador reinterpreta como copertenencia de Dasein y ser. Así, en las Beiträge zur Philosophie Heidegger sostiene que: «la relación del $D a$ sein al ser pertenece al hacerse presente (Wesung) del ser (Seyn) mismo, lo que también puede ser dicho así: el ser (Seyn) necesita al Da-sein, no se hace presente sin ese acontecer apropiador (Er-eignung)»». ${ }^{29}$

A juicio de nuestro pensador, la noción e idea del Ereignis es la única que puede ofrecer una alternativa al presencialismo. Tal alternativa pasa por negar a la ousía su carácter directivo para otorgárselo a lo que es en el sentido de la

27 «Sein kann nicht sein. Würde es sein, bieble es nicht mehr Sein, sondern wäre ein Seiendes», «Kants These über das Sein», Wegmarken GA 9, p. 479.

28 Aunque no es posible dar cuenta aquí del estado actual de la investigación con relación a esta temática, menciono a continuación algunos estudios que considero de referencia: D’Angelo, A., Heidegger e Aristotele: la potenza e l'atto, Il mulino, Napoles, 2000; Giusti, La potenza all'origine. Heidegger interprete di Aristotele, Napoli, La Città del Sole, 2000; Figal, G., Figal, «Heidegger und die Phänomenologie», en Das Spätwerk Heideggers. Ereignis-SageGeviert, Damir Barbaric (ed.), Königshausen, Würzburg, 2007, pp. 9-19; Hanley, C. «Force and dynamis in Aristotle and Heidegger», Analecta husserliana, 74, (2002), pp. 3-18; Ilting, K.-H., «Sein als Bewegtheit. Zur Heidegger Von Wesen und Begriff der Physis, Aristoteles Physik B 1», Philosophische Rundschau, 10, (1962), pp. 31-49; Mora, Francesco, L'ente in movimiento: Heidegger interprete di Aristotele, Padova, Il Poligrafo, 2000; Oberst, A., «Heidegger's appropiation of Aristotle's Dynamis/Enérgeia distinction», American catholic philosophical Quarterly, 78, (2004), pp. 25-51; Polt, R., «Einführung in die Metaphysik: eine Erkundung der physis und ihre Entmachung», Heidegger Handbunch, Stuttgart, 2003, 174-181; Sheehan, Th., «Heidegger's Interpretation of Aristotle: dynamis and enérgeia», Philosophy Researche Archives, 4, (1978), pp. 278-314; Sheehan, Th., «On the way to Ereignis: Heidegger's Interpretation of Physis», Continental Philosophy in America, H. Silverman, J. Sallís and T. Seebohm (eds.), Pittsburg, Duquesne University Press, 1983, pp. 131-164; Sheehan, Th., «Kehre and Ereignis», en Heideggers Introduction to Metaphysics, Richard Polt y Gregory Fried (eds), Yale university Press, New Haven and London, 2001, pp. 3-17: Sheehan, Th., «Facticity and Ereignis», en Dahlstrom Daniel O (ed.), Interpreting Heidegger. Critical Essays, Cambridge University Press, 2011,42; Volpi, «La riabilitazione della dynamis e dell' enérgeia in Heidegger», Aquinas, 33, (1990), pp. 3-28; Volpi, Franco, Heidegger y Aristóteles, Fondo de Cultura Económica, México, 2012, p. 176.

29 Beiträge zur philosophie, GA 65 \& 135, p. 254. 
enérgeia, aunque atelés.

III.1. EL EREIGNIS. REAPROPIACIÓN Y TRANSFORMACIÓN DE LAS NOCIONES DE PHYSIS, ALÉTHEIA Y ENÉRRGEIA ATELÉS. ${ }^{30}$

A mi parecer no es posible hacerse cargo del proyecto heideggeriano titulado «Ereignis» sin tomar en cuenta la reinterpretación fenomenológicohermenéutica de las aristotélicas nociones de physis, alétheia y enérgeia.

Miradas las cuestiones con cierto detenimiento, encontramos un importante punto de coincidencia entre la ontología aristotélica y la filosofía heideggeriana. Se trata de la pregunta por el movimiento, que en ambos pensadores es determinante. En el caso de Aristóteles se trata de la pregunta por el movimiento de la naturaleza. En el de Heidegger, la pregunta por el movimiento es también central por su directa vinculación con el tiempo. Pero, además, esa pregunta es también central en el pensador de Ereignis porque el «llegar a la presencia» de la verdad y el sentido constituye un cierto tipo de movimiento.

Hay que tener en cuenta que la de Heidegger es una «ontología fenomenológica» en el sentido de que se pregunta, No por el ente, sino por la «verdad» del ser; esto es, por su sentido. Un sentido que es posible, a juicio del Heidegger maduro, merced a la copertenencia de Da-sein y ser. Esto es, a una novedosa modulación de la sentencia de Parménides de acuerdo con la cual «lo mismo es pensar y ser». ${ }^{31}$ Pues bien, el Ereignis no es nada diferente a lo que permite la donación de sentido. Así, por citar un ejemplo, en «Der Satz der Identität» Heidegger sostiene: «Pero el ser mismo nos pertenece, pues sólo en nosotros puede presentarse como ser, esto es, llegar a la presencia». ${ }^{32}$

Lo que interesa a Heidegger es lo que hace posible que haya verdad y sentido, teniendo en cuenta que se trata de un movimiento; el de llegar a la presencia. Precisamente aquí es donde se hace operativo el hallazgo aristotélico de la enérgeia atelés. Una noción íntimamente vinculada, como sabemos, a las de physis y dynamis. Sin duda, la comprensión aristotélica del movimiento como «acto de lo potencial en tanto que tal» ${ }^{33}$ parece resultar adecuada para ella. Pero se ha de tener en cuenta que en la definición aristotélica el movimiento

30 En una investigación mía de próxima publicación, titulada «Heidegger: el Ereignis desde la reapropiación de la respuesta aristotélica al problema del movimiento» profundizo con más detenimiento en algunas de las cuestiones que expongo aquí a continuación de manera sucinta.

31 Fragmento 18.

32 «El principio de Identidad» en Identidad y diferencia, Anthropos, Barcelona, 1988, trad., Helena Cortés y Arturo Leyte, p. 79 (Identität und Differenz, Neske Verlag, Tübingen, 1957, $4^{\text {a }}$ ed., p. 20.

33 Física 201a 10-11. 
adquiere el estatuto de enérgeia; el movimiento es acto de lo potencial, pero no es lo potencial, ni es potencial, porque es acto.

Si realizo esta observación es porque del mismo modo que sería erróneo identificar, según el estagirita, kínesis y dynamis, lo es identificar en Heidegger la «llegada a la presencia» con esa misma dynamis. Así, la mencionada «llegada a la presencia» del ser o del sentido, no es entendida por el autor de Sein und Zeit desde la potencia sino desde el acto, aunque imperfecto. En consecuencia, habría que sostener que el sentido directivo del ser no es para Heidegger la dynamis sino la enérgeia. Esto es así a pesar de que Heidegger criticara a Aristóteles por situar el acto por encima de la potencia ${ }^{34}$ y a pesar de la enorme importancia y atractivo que siempre tuvo para el pensador de ser la mencionada dynamis.

\section{III.1.1. ENÉRGEIA Y ENÉRGEIA ATELÉS.}

Como ya he recordado, en el Natorp Bericht Heidegger sostiene que la enérgeia es el resultado de una «radicalización ontológica de la idea de movimiento». Algo que no parece alejarse de Aristóteles, pues él mismo sostiene que parece que el acto es fundamentalmente el movimiento: «la palabra acto (enérgeia), vinculada a la realización perfecta (entelécheia), se ha extendido también a otras cosas, fundamentalmente a partir de los movimientos. En efecto, parece que el acto es, fundamentalmente, el movimiento. ${ }^{35}$ Así pues, el acto no sería sino una modulación perfecta del movimiento. Aquella en la que está ausente toda carencia porque en él se dan simultáneamente el fin y la acción. ${ }^{36}$ Se trata de «movimientos perfectos», como el ver o el ser feliz. Movimientos que constituyen la más alta actividad en reposo. Así lo entiende Heidegger en «Von Wesen und Begriff der Physis. Refiriéndose al ejemplo aristotélico de ver aclara que

Sólo es en realidad máxima movilidad en el estado de reposo del ver (simple) recogido en sí mismo. Este ver es el Télos (...). Así pues, la movilidad de un movimiento consiste sobre todo en que el movimiento de lo móvil se reinicia en su final, télos, y, en cuanto tal reiniciado en el final, se «tiene»: en télei échei: entelécheia, el tenerse a sí mismo al final. ${ }^{37}$

Aunque expresándose de un modo no convencional, la interpretación

34 «Sobre la esencia y el concepto de Physis. Física B 1», Hitos, Alianza, Madrid, 2000, trad. Helena Cortés y Arturo Leyte, p. 236 (GA 9, p. 286).

35 Metafisica IX, 1047a 30-33.

$36 \quad I b ., 1048$ b 18-34.

37 «Sobre la esencia y el concepto de Physis», op. cit., p. 235 (GA 9, p. 284). 
heideggeriana del acto parece correcta. A renglón seguido del texto que se acaba de citar precisa nuestro pensador que para «acto», además de la palabra entelécheia, Aristóteles usa el término enérgeia. ${ }^{38}$ La precisión no es irrelevante porque ayuda a mantener la vinculación entre acto y movimiento, tal como por otra parte hace el mismo Aristóteles cuando proporciona su definición de movimiento, tanto en Física I omo en Metafísica IX. Es en ambos textos donde el estagirita se decide a otorgar a la kínesis el estatuto de acto al no advertir otra posibilidad de comprensión, y ello a pesar de las dificultades que tal definición acarrea. El movimiento, dice Aristóteles, es «la actualización (enérgeia) de lo que está en potencia en tanto que tal». ${ }^{39}$ Dicho de otro modo, el movimiento es un «estar en obra» que se mantiene mientras lo potencial siga siendo potencial y que sólo cesa - deja de ser acto- cuando eso ha alcanzado su fin: se ha actualizado, está en acto.

Ahora bien, lo que a lo largo de sus interpretaciones maduras de Aristóteles destaca particularmente Heidegger con relación al acto entendido como un «Am-werk-sein» es su «dimensión fenomenológica», por eso lo vincula a lo que él denomina «el presenciar»: la llegada o salida de la presencia en que consiste la ousía. Más específicamente, interpretando a Aristóteles y partiendo de que es el estagirita quien atribuye a la ousía el carácter de la actualidad, sostiene que «la presencia, ousía, se llama, por eso, enérgeia: esencia-como-obra en la obra («esencia» entendida verbalmente), La obridad. Ésta no alude a la realidad efectiva como resultado de un efectuar, sino al presenciar que está-ahí, en lo desoculto, de lo pro-ducido, allí puesto e instaurado». ${ }^{40}$ En consonancia con esto, hemos de concluir dos cosas. Por una parte, Heidegger parece entender el acto como un cierto «acontecimiento» (Geschehen). Por otra, se trata de un «acontecimiento» de sentido.

Es ahora, en el último giro de la interpretación sobre la noción aristotélica de acto, donde Heidegger parece alejarse del Aristóteles «canónico». Lo hace en un intento de aproximar la doctrina aristotélica a su proyecto fenomenológico-hermenéutico denominado Ereignis.

III.1.2. PHYSIS, ALÉTHEIA Y ENÉRGEIA ATELÉS.

En «Von Wesen und Begriff der Physis» Heidegger realiza una porme-

38 Cf. $I b$.

39 Metafisica XI, 1065b 16-17.

40 Nietzsche, op. cit., p. 331 (GA 6.2, p. 404). 
norizada interpretación de los primeros libros de la Física aristotélica. No se trata de una interpretación convencional. Su objetivo es mostrar la identidad de physis y alétheia o lo que es lo mismo: que al ser le pertenece el surgir y el desocultamiento-ocultamiento. Pues bien, en ese «surgir» o «llegar a la presencia» está implicada la aristotélica noción de enérgeia atelés.

Como ya he apuntado antes, la perspectiva heideggeriana no es desde luego óntica sino fenomenológica. Lo que importa a nuestro pensador es el acontecimiento de la verdad que ahora se localiza en la «venida a la presencia» de la physis, es decir (como veremos), de la forma.

Heidegger identificó, aunque para ello le faltara el apoyo textual, la physis con el ser. Se trata también de una identificación fenomenológica, en el sentido de que la physis, en cuanto ser, es lo que hace posible que el ente se muestre, que acceda a la presencia. El ser como «das aufgehend-verweilende Walten ${ }^{41}$ es lo que permite la salida y la llegada a la presencia. A tal «brotar desde sí» le pertenece, como su esencia, la movilidad (Bewegtheit). Pues bien, Aristóteles afirma lo siguiente: «Damos por supuesto que las cosas que son por naturaleza, o todas o algunas, están en movimiento». ${ }^{42}$ Lo que significa, a juicio que Heidegger, que Aristóteles

fue el primero en alcanzar o incluso en crear ese grado de preguntar desde el que (...) el ser en movimiento es concebido y cuestionado expresamente como el modo fundamental del ser. Pero esto significa que la determinación de la esencia del ser no es posible sin la mirada esencial a la movilidad en sí. ${ }^{43}$

Importa destacar la idea de que el ser en movimiento fuera concebido como el modo fundamental del ser. El autor de Sein und Zeit no llega a afirmar que el de la Física erigiera el movimiento como sentido directivo del ser. Pero la afirmación aristotélica que acabo de citar da pie a Heidegger para abrir la posibilidad de una «ontología fenomenológica dinámica». Veámoslo.

Siguiendo a Aristóteles, quien se pregunta qué es lo que es propiamente physis, si la materia o la forma ${ }^{44}$, Heidegger repite que es la morphé. Con Aristóteles, «hé morphè kaì tò eîdos tò katà tòn lógon»». ${ }^{45}$ Lo que estaría implicado en esta respuesta es que el estagirita entiende la morphé desde el eîdos. Ahora bien, eîdos significa el aspecto de algo que comparece en el lógos, es lo que llega a ser al ser visto. Por tanto, Heidegger puede concluir que la morphé se sitúa de lleno en el ámbito de la verdad y el sentido. De ella sostiene que

41 Einfürhung in die Metaphysik, GA 40, p. 16.

42 Física A, 185a 12ss.

43 «Sobre la esencia y el concepto de Physis», op. cit., p. 203 (GA 9, pp. 243-4).

44 Física II, 1.

45 Física, 193a 28-31. 
Por un lado, [es el] establecerse en el aspecto como modo de la venida a la presencia, ousía; morphé no como una propiedad presente en la materia, es decir, que es en ella, sino como un modo del ser [sentido]; por otro lado, [es] el «establecerse en el aspecto» como movilidad, kínesis [enérgeia atelés], un «momento» [y esta precisión no se puede obviar] que falta por completo en el concepto de forma. ${ }^{46}$.

Que la morphé sea un modo de ser y no un ente es algo que guarda directa relación con la copertenencia de Dasein y ser. Heidegger había afirmado ya en 1927 que hay ser -verdad y sentido- en la medida en que el Dasein es. El ser comparece en el lógos, en el lenguaje, y éste es ahora apertura: Lichtung. Por otra parte, que la morphé es un «establecerse en el aspecto» remite a su carácter de kínesis (que ha de ser entendida como enérgeia atelés). Pero se trata del movimiento de la naturaleza y por tanto es, específicamente, metabolé, génesis. Ahora bien, según Aristóteles «la naturaleza entendida como generación es un proceso [odós] hacia la naturaleza entendida como forma». ${ }^{47}$ Por lo tanto, concluye Heidegger, en ella se muestra algo que hasta entonces estaba ausente. En definitiva, la physis se puede entender como un «producirse a sí misma» ${ }^{48}$ y también, por ello mismo, como un venir a la presencia.

Éste es el objetivo último que parece perseguir el intérprete de Aristóteles: mostrar que la morphé es venida a la presencia y salida de ella, que le pertenece, por tanto, la dinámica de ocultación/desocutación y que es así como es enérgeia atelés y a la vez alétheia, puesto que se trata de un mostrarse incompleto del ser. Así pues, con Heidegger nos encontramos ante lo que podríamos denominar una «fenomenología de la Anwesung» que se opondría a la tradicional «ontología de la Anwesenheit».

Pero esto no es todo. Acabamos de recordar que la physis es génesis y, en consecuencia camino. Heidegger recurre al ejemplo del capullo, la flor, el fruto y la semilla para hacer entender que la physis «es ese apartarse a sí misma que la produce a ella misma». ${ }^{49}$ Pero a la génesis le pertenece la stéresis, que podría ser entendida como un «presentarse del ausentarse». ${ }^{50}$ Esto, a juicio de Heidegger, significa tanto como que «en la stéresis se oculta la esencia de la physis ${ }^{51}$. De hecho, es en la stéresis donde Heidegger encuentra el mejor modo de mostrar que la physis es el movimiento mismo de ocultación/desocultación. Ahora bien, lo que esto significa en definitiva es la identidad de physis y alétheia:

46 «Sobre la esencia y el concepto de Physis», op. cit., p. 276 (p. 228).

47 Física, 193b 12-13.

48 «Sobre la esencia y el concepto de Physis», op. cit., p. 289 (p. 239).

$49 I b .$, p. 298 (p. 246).

50 Es Aristóteles quien afirma que «la privación es de alguna manera forma». Física, 193 b 18-20.

51 «Sobre la esencia y el concepto de Physis», op. cit., p. 245 (GA 9, pp. 296-7). 
los fenómenos han de ser arrancados de su ocultamiento, al que vuelven como la rosa brota de su semilla y desaparece en ella.

Merced a la identificación señalada, Heidegger vincula ser, sentido y surgimiento o enérgeia atelés. Lo hace de una manera explícita al afirmar en el Nietzsche que «en el comienzo de su historia, ser se despeja como surgimiento (physis) y desocultación (alétheia)». ${ }^{52}$ Tal despejarse tiene la índole de la enérgeia atelés.

Heidegger realiza una lectura fenomenológico-hermenéutica de la Física de Aristóteles. ${ }^{53} \mathrm{Tal}$ lectura está situada, como se ha querido mostrar, en el horizonte del Ereignis y sirve a ese propósito que quiere volver a comprender la identidad de pensar y ser.

\section{CONSIDERACIONES FINALES}

1. No cabe duda: existe una diferencia fundamental entre el planteamiento filosófico de Heidegger y Aristóteles. Ésta tiene que ver, entre otras razones, con el enfoque y orientación que cada uno de ellos proporciona a su investigación. La del de Friburgo está marcada, en definitiva, por la exigencia de atender a la diferencia ontológica. A Aristóteles le importa dar cuenta del ser de lo que es, por eso se pregunta por lo que es en cuanto que es, pero no se puede olvidar que ese ser es la forma - es decir, la entidad-y nada más. Así consta, por ejemplo, en el capítulo decimoséptimo del libro VII de la Metafísica: «La entidad es esta naturaleza que no es elemento, sino principio». ${ }^{54}$

La ousía no es cosa, por lo que bien se podría decir que pertenece al orden ontológico y no al óntico. Esto es verdad, al menos si permanecemos en el horizonte aristotélico. Sin embargo, situados en el heideggeriano, aunque el descubrimiento acerca del carácter principial de la forma sea trascendental, no alcanza a cubrir lo que Heidegger destacó al establecer la diferencia entre ser y ente.

La ontología aristotélica está íntegramente gobernada por la pregunta por el por qué, pero de ella está ausente la pregunta por la condición última de posibilidad, aquella que no pertenece al orden de lo posibilitado, entre lo que también se encuentra la forma como principio. «Queda claro [dice Aristóteles] que no se pregunta por qué es hombre el que es hombre: se pregunta, más bien, por qué algo se da en algo (...) Es, desde luego, evidente que se pregunta la

52 Nietzsche, op. cit., p. 330 (GA 6.2, p. 403).

53 Con relación a la ontologización de la fenomenología y la fenomenologización de la ontología, cf. Figal, «Heidegger und die Phänomenologie», en Das Spätwerk Heideggers. Ereignis-Sage-Geviert, Königshausen, Würzburg, 2007.

54 Metafisica, VII, 17, 1041b, 16-31. 
causa y ésta, hablando lógicamente, es la esencia». ${ }^{55}$

Que la pregunta heideggeriana sea de otra índole, que no se mueva en el mismo plano, ha sido motivo, en no pocas ocasiones, de malentendidos, comenzando por el propio Heidegger, quien, especialmente al principio de su camino criticó algunos aspectos de la interpretación aristotélica que, en realidad, no tenían por qué ser objeto de reprobación. Así, en realidad, como he señalado al comienzo de estas páginas, no hay crítica a la comprensión aristotélica de lo real. Más bien lo que hay es una llamada de atención: lo presente, aquello que asiste de manera constante, no es ni puede ser lo último. También porque no explica todo: no explica el carácter dinámico, temporal e histórico del ser.

Fue el propio Heidegger quien advirtió lo desenfocado de algunas de sus críticas cuando, al madurar su interpretación de Aristóteles, comprendió que, en realidad, su pregunta no era la misma ni se situaba en el mismo plano que la del estagirita. Y no lo estaba por lo que se ha dicho al principio de este epígrafe: porque su inquisición estaba guiada desde la diferencia ontológica.

2. En su interpretación de la ousía aristotélica hay algo en lo que Heidegger resulta certero. Se trata de que el criterio para la determinación de lo que sea ousía es temporal. En la expresión heideggeriana «lo que yace ahí delante» se destacan dos aspectos. El «yacer», el ser sujeto y el «estar ahí delante», el estar presente. Respecto a ese «yacer» no tenemos especiales dificultades, puesto que sabemos bien que la sustancia es sujeto, aunque determinado. Sabemos también que ese ser sujeto está establecido desde el lenguaje, como se pone de relieve no sólo en el capítulo cuarto de las Categorías sino también en la Metafísica (IV, 4 y VII, 3). Por lo que hace al «estar ahí delante», presente, los textos no parecen en principio tan explícitos, pero hay que tener en cuenta que para que algo sea sustancia es menester que sea acto o que esté en acto: que sea actualmente lo que es. ¿Cómo hay que entender ese ser o estar en acto?

«Decimos que una cosa es lo que es cuando existe actualmente más que cuando existe en potencia». Pero lo que la potencia dice es el «todavía no», por eso mismo sostiene Aristóteles que «el acto es anterior a la potencia» ${ }^{56}$ en cuanto a la noción, la entidad y el tiempo. Pues bien, lo que explica Heidegger es que

La enérgeia lleva a término de modo más originario la esencia de la pura venida a la presencia en la medida en que significa el estar-en-obra y tenerse-al-final que ha dejado tras de sí todo aquel 'todavía no' del carácter adecuado para..., o, mejor aún, lo ha llevado consigo y hacia delante en la plenitud del aspecto completamente terminado. ${ }^{57}$

$55 I b ., 1041$ a 22-28.

56 Metafisica IX, 8, 1049b 10ss.

57 «Sobre la esencia y el concepto de Physis», op. cit., p. 237 (GA 9, p. 287). 
Cuando Aristóteles explica su definición de movimiento, utiliza el criterio temporal: «cuando lo construible, en tanto que decimos que es tal, está en actualidad, entonces está siendo construido: tal es el proceso de construcción ${ }^{58}$. Lo mismo se puede ver en el pasaje correspondiente de la Metafísica, aunque de forma todavía más explícita: «cuando lo edificable -en tanto que decimos que es tal- está actualizándose, se está edificando, y esto es la edificación (...). Y el movimiento ocurre cuando se da la realización misma, ni antes $n i$ después» ${ }^{59}$ Por último, otro texto del mismo capítulo y libro de la Metafísica: «Movimiento es la realización de lo potencial en tanto que potencial. Que es ésta y que el movimiento ocurre cuando se da la realización misma, y no antes ni después, es obvio»». ${ }^{60} \mathrm{Y}$ también: «y la actualización de lo edificable, en tanto que edificable, es la edificación». ${ }^{61}$

Todo esto pone de manifiesto que el criterio para la determinación de lo que es ousía y enérgeia (ambas nociones están unidas indisolublemente en Aristóteles) es temporal; que, en concreto, la presencia, el ser en presente es determinante para que de algo se pueda decir que es una sustancia y que, por lo tanto, es acto o está en acto. Sin embargo, no se nos escapa que la comprensión de la enérgeia sufre una transformación o reorientación a lo largo del camino de Heidegger. Si en los primeros años nuestro pensador se aferra al contenido de actualidad, vinculado a la presencia, para criticar la metafísica aristotélica, a partir de entonces se centrará especialmente en el carácter de «estar en obra» del estar operando, es decir, al carácter de operación que caracteriza esencialmente esta aristotélica noción. Al hacerlo, Heidegger logra una interpretación que, por una parte, se ajusta más a aquello de lo que Aristóteles quería dar cuenta aunque, por otra, se aleja decididamente de la vinculación que esta noción guarda con la ousía. Lo cierto es que parece necesario superar la centralidad y ultimidad que detenta la noción de sustancia puesto que ésta puede llegar a ensombrecer las virtualidades contenidas en la noción de acto. En efecto, la enérgeia, tal como la entiende Aristóteles contiene en sí todo lo necesario para proporcionar una «ontología dinámica», aunque para lograrlo se haya de desvincular de una concepción presencialista de lo que es. En la Metafísica aristotélica hay momentos (así en el libro XII) en que parece que el acto está por encima y más allá de la ousía, sin embargo, habitualmente se mantiene entre ambas nociones una correspondencia biunívoca. En cualquier caso está claro que, de acuerdo con Heidegger, la enérgeia podría constituirse como sentido directivo del ser, puesto que éste acontece, es histórico temporal, del

58 Física III, 1, 201a 17-19. El subrayado es mío.

59 Metafísica 1065b 17-21. El subrayado es mío.

$60 I b ., 33-35$. El subrayado es mío.

$61 \quad I b ., 1066$ a 2-3. 
mismo modo que lo es el Ereignis. Ésta es la razón que le permite a Heidegger vincular productivamente para su proyecto physis, alétheia y enérgeia.

Carmen Segura Peraita es profesora titular de Filosofía Teorética de la Universidad Compútense de Madrid.

Linea de investigación:

Heidegger; Hermenéutica contemporánea y actual (Heidegger y Gadamer) en su diálogo e interpretación de la filosofía griega (en particular, Aristóteles). Especializada en ontología, metafísica e historia de la filosofía antigua y contemporánea (hermenéutica contemporánea y actual).

Dirección Postal:

Facultad de Filosofía (ed.A), Ciudad Universitaria s/n, 28040, Madrid

Correo electrónico:

csegura@filos.ucm.es 
